\author{
Shavtvaladze Nana \\ University of Georgia, Georgia
}

\title{
The Art of Persuasion in a Multicultural world
}

\begin{abstract}
Together with grammar and vocabulary, there are many other points that determine Georgian mentality and perception, while teaching Georgian as a foreign language. Language is a representative of the nation and national self-awareness. It is unimaginably hard to differentiate the language, determine the actions and criticize when you are an active and essential part of the same world. It is the same as the air that you breathe but do not feel how polluted it is. Our actions and answers are automatic. That is why each person represents his/her cultural mentality and language reveals it.

The world changes and the process of globalization influences the nations and every representative of the culture. A human being is the face of his/her country and the forms of the language used there. People might migrate to different countries and gain a new lifestyle, this process even more interestingly displays the merging process of the old and new cultures and its possible result. The desire for unity appears when the process of globalization and bordering starts. People`s approaches to the living rules match, when it comes to the emulating and bringing something into the fashion according to the society classes. So, the values are the same, but the cultural views differ.

Every nation has a different cultural approach. The reflection of the uniqueness and characteristics of the nation is exactly in this. If we don't have a word and we find it in the process of translation, this means that our ancestors didn`t need it, didn`t create it as it wasn`t necessary for them. The Georgian language is always open to development; it accepts the innovations and generation challenges. It's true that the calques and barbarisms are an accompanying process, but every novelty has its name and the language accepts it or revives it properly to the language.

Generation approaches are taken into consideration when it's about creating the map of cultural mentality. Each period of twenty years influences the nation's development, it's views and approaches. Changes are inevitable processes, traditions are transformed, novelties and emulating are being settled, especially for the representatives of new generation. The mental struggles and battles between the fathers and children continue. Older generations were more distant, shy and respectful to the elders; they even used other lingual capacities. Modern generations prefer to use polylogic forms. Besides this, this is a skillful generation and we have a hope for them to save and develop the language: "Motherland prefers to have a better child than his/her father".

The difference between the old and new generational approaches is obvious, especially in terms of convincing and leadership. Modern people are more convinced about their future. They start fighting for their goals from their early years, their self-consciousness is high and almost every second young person considers himself/herself as a leader.
\end{abstract}


The biggest determining factor of the mentality is different for every nation. Geopolitical state also decides the mentality, but the primary qualitative function is multiple. Emotion is the steady basis for Georgian mentality. Emotion is the one that makes Georgian selfconsciousness special and marvelous. Emotion is a featuring thing for every Georgian generation. The conception of youth about the convincing and leadership, also, the process of managing the cultural map was very interesting for us. That was why we offered the following survey:

Here are the methods that were used during the survey:

- Research Method - Quantitative research

- Research Technology - Submitted, group questioning

- $\quad$ Target segment - Students

- Sample form - Convenient selection

- $\quad$ Sample size - 100 students - 1 st and 2nd courses

According to the SPSS, the data were input.

1. Question: First of all in order to convince another person do you consider your principles or do you use these guidelines?

People in their early twenties consider principles as primary: $81 \%$ principles as main; $19 \%$ based on the instructions.

2. Question: Which type of leader do you prefer: equal or the one following hierarchical principles?

Opinions are divided into two parts when it came to the subject of leadership and managing: $50 \%$ equal, $50 \%$ hierarchic.

The creation of the Georgian cultural map has a long route to cover. It is a new stage after several attempts. It is obvious that principles are important and a little bit instructed for Georgians, we might make decisions based on the recommendations. Unfortunately, leadership wasn`t obviously shaped, the percentage was divided into two equal parts, some prefer equality, some prefer hierarchy. Lingual aspects that are used for processing the perception of this function are utterly interesting.

Key words: grammar and vocabulary, cultural approach, multiculturalism.

Language is representative of the nation and national self-awareness and, due to this fact, it clarifies the attitudes towards every point. It's unimaginably hard to differentiate the language, determine the actions and criticize when you 're an active and essential part of the same world. It's the same as air, you breathe but don't feel how polluted it is. Our actions and answers are automatic. That's why each person represents his/her cultural mentality and language reveals it.

World changes and the process of globalization influence the nations and every representative of the culture. A human being is the face of his/her country and the forms of the language used there. Of course people might migrate to different countries and gain a new lifestyle, this process even more interestingly displays the merging process of the old and new cultures and its possible result. The desire for unity appears when the process of globalization and bordering starts. People`s approaches to the living rules match, when it comes to the emulating and bringing something into the fashion according to the society classes. So, the values are the same, but the cultural views differ.

Every nation has a different cultural approach. The reflection of the uniqueness and characteristics of the nation is exactly in this. If we don't have a word and we find it in the process of translation, this means that our ancestors didn`t need it, didn`t create it as it wasn`t necessary for them. 
E ISSN 1512-3146 (online) ISSN 1987-9601 (print)
International Journal

of Multilingual Education

Such is the word - "maintain", which is actively used in English language. The direct translation of this word in Georgian has the meaning of "shenarchuneba", but it doesn 't express the same meaning it comprises in English according to the context. When translating the word "maintain" in Georgian, we can use it in terms of to fix/to repair, to renovate, to renew, to preserve, etc. Culturally we don't rebuild our houses every year, we don`t repaint the rooms every spring, etc. We don`t have the exact translation of this word, as we don`t use these activities in the same context. Example given, exactly describes our situation: 'The home maintenance schedule template details quarterly, seasonal tasks to keep your house in good working order.' According to this situation, we can barely use the expression "to maintain the house", we'd rather say - to rebuild the house, to repair it, to renovate it. The same can be said about the word "moderate", which is translated as "zomiereba (keeping with the bounds)". As we are the maximizing nation, it's hard for us to keep the balance and gold limits. This is why we rarely use or don't use this word with its meaning at all. 'a person who has moderate opinions or is a member of a moderate political group'. Even in this situation it's unacceptable for us to express our opinions with phrases like: "moderate opinions" or "moderate political group". We represent the essence in a different way, but it's undeniable that the definition of the word "moderate" doesn't go as far. We can say "s/he had her/his moderality food", "S/he gave me a moderality reprimand" etc. but we don't say "moderate opinions". Probably, we might say s/he defined, designated his/her opinions smoothly or we might give it another interpretation. When studying a foreign language, foreigners pay attention to the inner structure of the language, its development, influences and thoroughly percieve the development of wordbuilding. This proves the character expression, cultural approaches and the characteristics of the nation.

According to our experience and insight, cluster working is very successful for the lexis. Using this approach, you pay attention to the roots and opportunities of production. Determining the root, you highlight the learner`s mind and make it closer to Georgian consciousness and the cultural form of the country. For example, the word "Ga-marj-oba!" we split this word in parts and explain the meanings of each segment. Gathis is a preverb, which determines the direction from narrator to the listener; Root - marj; -oba - producer of the abstract word. We explain the meaning of the root "marj"; what does the word "marjve" mean for the Georgian people; We get "marjvena (right)", which is thouroughly important for the Orthodox nation "right hand; an angel standing on the right, etc.". This is the very word out of which we get "gamarjveba (victory)", the Georgian people have always been seeking for. This is why, when Georgians meet the greet each other and wish each other to be adroit, have a day beautified by the angel and victory. "Gamarjoba/gamarjobat". The form "gamarjobat" was unacceptable, it used to be taught to omit - $t$ from the end. This is a copung word, which has the marker of verb production, ga - preverb; why shouldn't it have " $\mathrm{t}$ ", as " $\mathrm{t}$ " is considered as the polite form marker and the plural form marker, while "oba" is a suffix for abstract producer.

The word "damelodet (wait for me)" is very interesting and describes Georgians` inner nature. Just like everyone, from different nations, we also, especially we Georgians hate waiting. It's hard and unacceptable for us, for such active, emotional people. You can clearly see this in our round and non- rectilinear queues, while driving cars and so on. We claim that this is an un-pleasant process for everyone, but it's an unimaginable process for the emotional Georgian. This is why, when it comes to the definition of the word "da-m-elod-e" it becomes clear, that da- is the preverb, which doesn't describe the direction, but it describes the intensity, movement, anxiety. The root "lod" - is a rock (Lodi), which is the biggest stone. When defining this process, old Georgian linked his/her emotions of the period of waiting to holding a heavy rock. , which means that waiting is as hard as holding the heavy rock for his/her consciousness and exactly knows that he won't be able to wait for long, just like he won`t be able to hold this stone for long. Having explained this to the foreigner, it becomes clear for him/her why we can't calmly stand in the queus and wait.

There might be many questions about the you - singular/ informal and you - plural/ formal. Older generation prefers to keep the polite, you (plural/formal) form; in spite of this fact they can easily turn to you singular/ informal form, when it comes to the conversation with the newly met person. This describes that this 
person is ready for sharing "goba" (Megobroba - Friendship). This is considered as a cultural activity, as the respect is always shown to the older generation and to the guest by the Georgians and this is why s/he chooses to use you (singular/informal form), as the sign of friendship and support. Younger generations always use you singular/informal when talking between each other. When it comes to the official work, where subordination should be highlighted, you plural/ formal is used.

It s worth paying attention when referring to each other we might use different expressions, these expressions might be considered as quarrels or negative actions. But these are just emotional references to each other, which is full of kindness, joy and positive forms. As for me, when the surroundings are warm, people are also full of love and extra emotions, but we need to say that we can`t share this, just like it was about the queus and driving the cars.

We need to highlight the form of negation which is always at the center of attention among the foreigners. Double negation is natural part of Georgian language. In order for the saying to be correct, we define it and sometimes we not only define but add negative particles as well, pronouns or adverbs. For example : -no,no, i'm not coming,- no, no I don`t want to come; yes-yes, for sure; no, no I can`t come; don't - don`t say that; - no one, no one dare calling about you; no one loves me; - I won`t go "nowhere"; - I couldn`t find the medicine "nowhere"; don`t go "nowhere".

We always choose systematic attitude, so the form of derivation is defined. According to the principle of aglutination, every function has its marker. Such an organized system helps the student to easily perceive complex constructions. For example, possession can be expressed with the possessive case together with the demonstrative pronouns.

Word building is a way of development a language. Here as well, the systematic attitude leads the inner structure of the language, together with a lot of prefices, suffices, we can create new words and after activating them you can meet them with changes. For example: tovli (snow) - tovliani (snowy - tovs (it`s snowing); khati (icon) -mkhatvari (artist) - sakhati - nakhati (painting) - samkhatvro ( adj. drawing) - mkhatvruli (fiction dakhatuli (painted - dasakhati (ready to be painted) - khatavs (is drawing) - mkhatavs (is drawing me). Language code describes the the characteristics of the people.

The Georgian language is always open to development; it accepts the innovations and generation challenges. It's true that the calques and barbarisms are accompanying process, but every novelty has its name and the language accepts it or revives it properly to the language. The language can accept every challenge or not, it might deny or make it its own. We have a lot of examples of such cases. First meeting, when the student leaves the lessons with almost 40 new words, his condition becomes impressive, makes his motivation bigger and makes him enjoy studying. With a high sense of joy he continues studying a new, hard language. These are those international words that are used in many languages, including Georgian. For example: words with vowel endings are easily adapted: opera, visa, metro... Consonant ending words get $-\mathrm{I}$ at the end: proeqti (project); pasporti, banki...

Generation approaches are taken into consideration when it's about creating the map of cultural mentality. Each period of twenty years influences the national development, it's views and approaches. Changes are inevitable processes, traditions are transformed, novelties and emulati are being settled, especially for the representatives of a new generation. The mental struggles and battles between the fathers and children continue. Old generations were more distant, shy and respectful to the elders; they even used other lingual capacities. Modern generations prefer to use polylogic forms. Besides this, this is a skillful generation and we have a hope for them to save and develop the language: "Motherland prefers to have a better child than his/her father".

The difference between the old and new generational approaches is obvious, especially in terms of conviction and leadership. Moderns are more convinced about their future. They start fighting for their goals from early years, their self-consciousness is high and almost every second young person considers himself/herself as a leader. 
E ISSN 1512-3146 (online) ISSN 1987-9601 (print)
International Journal

of Multilingual Education www.multilingualeducation.org

The biggest determining factor of the mentality is different for every nation. The geopolitical state also decides the mentality, but the primary qualitative function is multiple. Emotion is the steady basis for Georgian mentality. Emotion is the one that makes Georgian self-consciousness special and marvelous. Emotion is a featuring thing for every Georgian generation.

According to psycholinguistic analysis, there are 8 forms that defines the main attitudes of the nation or people. These characteristics are important for the relationships, especially for the new ones. Erin Meyer, American researcher, states her opinion about this. She creates the books that describes her experience gained through travelling and sharing cultural attitudes with different nations, she states her perceptions and the evaluation scheme. Her research is truly impressive. If the foreigner knows the cultural map of the new country and has the information with the help of the schemes, it will make easier his arrival in a new country. So, he will have the information about this or that country and be psychologically ready to arrive in a new country. When discussing and analyzing, Erin Meyer has these cases: relationship, evaluation, decision, trust, denial, planning, persuassion and leading; Each of this is activated and defined with different nations of different cultures. Here they are:

Relationship - the quality of the relationship with each other and with foreign guests; how can it be valued? with high or low context.

Evaluation - Ho do we, Georgians, value things, events, actions, people? do we try not to express our opinions? is it direct or indirect evaluation from us.

Decision - how do we make decisions. is it hard or easy? is it discussed and agreed, or ordered from above?

Trust - what is trust in general, especially in business. We trust people that we know well, according to the tasks fulfilled or according to relationship. Trust can be expressed according to provement.

Denial - How confrontational or non-confrontational are our attitudes. Are we ready to go against or accept everything as it is.

Planning - what is our lifestyle, planned or based on the situations. Do we prefer scheduled time, or do we prefer flexibility?

According to the researches done previously, fifty youngers were surveyed (18-21 > age). According to SPS, data is listed like this: low - 0-20\%; lower than medium 21-40\%; medium 41-60\%; highr then medium 61-80\%; high 81-100\%. The perception of the young generation isn 't enough to understand the whole nation, but will help you to understand their attitudes. This generation meets the future with more motivation and loud announcements. Here it is:

1. Relationship $-41 \%$, high context; $9 \%$ low context.

2. Evaluation $-19 \%$ direct negations; $31 \%$ indirect

3. Decision $26 \%$ - ordered from above; $24 \%$ discussed and agreed.

4. Trust $-40 \%$ according to the relationships; $10 \%$ according to the tasks.

5. Denial - 36\% - confronatioanl; 14 non-confronational.

6. Planning $-31 \%$ flexibility; $19 \%$ scheduled time.

What about the persuassion and leadership, they underwent separate research.

Persuasion - what is more preferable for us, our own principles or do we obey the announcements and directions calmly.

Leadership - Are we teamworkers or do we prefer the hierarchic format.

The conception of youth about the convincing and leadership, also, the process of managing the cultural map was very interesting for us. That was why we offered the following survey:

Here are the methods that were used during the survey:

- Research Method - Quantitative research 
- Research Technology - Submitted, group questioning

- Target segment - Students

- Sample form - Convenient selection

- $\quad$ Sample size - 100 students - 1st and 2nd courses

According to the SPSS, the data were input.

1. Question: First of all, to convince one another do you consider your principles or do you use these guidelines?

People in their early twenties consider principles as primary: $81 \%$ principles as main; $19 \%$ - based on the instructions.

2. Question: Which type of leader do you prefer: an equal or the one following hierarchical principles? Opinions are divided into two parts when it came to the subject of leadership and managing: $50 \%$ equal, $50 \%$ hierarchic.

The creation of the Georgian cultural map has a long road to cover. It's at a new stage after several attempts. It`s obvious that principles are important and a little bit instructed for Georgians, we might make decisions based on the recommendations. Unfortunately, leadership wasn't obviously shaped, the percentage was divided into two equal parts, some prefer equality, some prefer hierarchy. Lingual aspects that are used for processing the perception of this function are utterly interesting.

It's preferable to to use the appropriate lexic when stating the subject and the characteristics of its cultural map. Active words, phrases, idioms, the ones that enrich and beautify our language.

\section{References}

Andreeva, 2009 - Андреева Г. М., (2009). Сочиальная психология, Москва, Аспект пресс.

Meyer, 2015 - Meyer, E., (2015). The Culture Map. Unatides State, PublicAffairs.

Shavtvaladze, 2014 - Shavtvaladze, N. (2014). Serya Biliki, Book I, Tbilisi, Forma

Shavtvaladze, 2015 - Shavtvaladze, N. (2015). Serya Biliki, Book II, Tbilisi, Forma

Shavtvaladze, 2016 - Shavtvaladze, N. (2016). Serya Biliki, Book III, Tbilisi, Forma 